\title{
Acciones de grupos terroristas del Próximo Oriente en España, 1975-1985*
}

\author{
DOMINGO JIMÉNEZ MARTIN \\ I.U. General Gutiérrez Mellado
}

\section{Actions of the Middle East terrorist groups in Spain, 1975-1985}

\begin{abstract}
RESUMEN
El objetivo de este informe es analizar las actividades de organizaciones terroristas de Próximo Oriente en España desde 1975 a 1985. Hoy la Jihad Global supone un nuevo capitulo en la historia del terrorismo. Los ataques terroristas a

EE.UU., Reino Unido o España representan golpes contra su «enemigo lejano". Sin embargo, mucho tiempo antes de los atentados del 11-S, el terrorismo internacional habia sido considerado como una de las amenazas más importantes a la seguridad. Se estudia el ataque terrorista contra el restaurante EI Descanso (abril, 1985), reivindicado por la Jihad islámica. Aquel atentado, cerca de la Base Aérea de

Torrejón (Madrid), fue un aumento importante en la escalada de violencia. El artículo termina con el fin de aquellas actividades.
\end{abstract}

PALABRAS CLAVES:

Terrorismo Internacional, Antiterrorismo, Secuestro, Jihad islámica, Abu Nidal.

\begin{abstract}
The objective of this report is to analyse the activities of Middle East terrorist organizations in Spain from 1975 to 1985. Today, the Global Jihad is a new chapter in the history of terrorism. Terrorist attacks upon USA, United Kingdom and Spain represent hits against their "far enemy". However, long before the 9-11 attacks, international terrorism had been considered as one of the most important threats to the security. The terrorist attack against El Descanso restaurant (April, 1985) is discussed. That bomb attack, near a US Air Force Base in Torrejon (Madrid), was an important raise in violence escalation (responsibility was claimed by (slamic Jihad). The article concludes with the end of those activities.
\end{abstract}

KEYWORDS:

International Terrorism, Anti-Terrorism, Kidnapping, Islamic Jihad, Abu Nidal.

* El presente artículo forma parte de un trabajo académico sobre "La Jihad Global en el sigio xxl: análisis sobre la amenaza asimétrica a la seguridad española en el marco mediterráneo", realizado bajo la dirección del profesor Juan Avilés. 
Desde el fin de la Segunda Guerra Mundial hasta la actualidad, el mundo árabo-musulmán entraría en una espiral de violencia en la que convergerían conflictos como el israelo-palestino, las rivalidades regionales de Oriente Próximo o la decadencia del nacionalismo árabe y el desarrollo del islamismo radical en su vertiente del salafismo jihadista. Actualmente percibimos la amenaza del terrorismo internacional como algo relativamente reciente. No obstante, durante la década de los setenta y ochenta la actividad política ejercida por los activistas árabes en el extranjero internacionalizó conflictos que hasta entonces parecían localizados a su ámbito geográfico. Aunque la internacionalización del terrorismo nunca ha sido monopolio de los grupos radicales del mundo árabo-islámico (basta recordar en aquella época a la Baader-Meinhof, las Brigate Rosse o el Ejército Rojo Japonés), sí empezarían a hacerse famosos por todo el mundo nombres como Abu Nidal, Al Fatah, Jihad Islámica o el Frente Popular para la Liberación de Palestina durante aquellas décadas de los setenta y ochenta.

Anuarios de terrorismo internacional de la RAND Corporation o la CIA establecían, aunque con cifras dispares, un ciclo de violencia terrorista internacional en la década de los setenta que habría tenido un punto importante de inflexión en la acción perpetrada por Septiembre Negro en los Juegos Olímpicos de Munich de 1972. El mundo entró aceleradamente en una era de internacionalización del uso del terrorismo más allá de las fronteras de las zonas en conflicto. El objetivo estratégico era crear miedo, lograr ventajas en las negociaciones, alcanzar concesiones y de manera inmediata obtener la máxima publicidad para su causa.

La España de aquellos años no fue ajena a ese proceso y lo que se pretende reflejar aquí es la evolución de un fenómeno que empezaría a irrumpir con cierta visibilidad en los años setenta. Se trataría de un ciclo que, aunque en sus orígenes carecía de componente religioso, terminaría desembocando en la perpetración por la Jihad Islámica del tercer atentado más sangriento de la historia de España: el del restaurante EI Descanso, reivindicado por extremistas islámicos en abril de 1985. Conviene recordar que la actual amenaza del terrorismo jihadista empezaría a infiltrarse en nuestro territorio durante la década de los noventa y habría empezado a calar en ciertos sectores de la población musulmana residente en España desde algunos años atrás. Por tanto, no se trata de buscar las raíces más o menos remotas de la amenaza actual. Se trataría de estudiar un fenómeno que llegó a establecer redes terroristas estables en nuestro país, como en el caso de la células islamistas chiíes de los ochenta, y que antes de terminar su ciclo perpetraría en abril de 1985 una de las matanzas terroristas más sangrientas de España.

En algunos casos, aquellos atentados pudieron ser motivados por ajustes de cuentas entre grupos terroristas o a la traslación de conflictos regionales a nuestro suelo. No obstante, los intereses norteamericanos e israelíes en nuestro país y la comunidad judía española figurarían como un objetivo terrorista preferencial. Décadas antes de la irrupción en el escenario global del terror jihadista internacional, 
el año 1975 fue catalogado como el «año del terrorismo"', perpetrándose acciones espectaculares como dos intentos de derribo de aviones comerciales en el aeropuerto de Orly en París, el secuestro de los ministros de los países de la OPEP en Viena o la ocupación de embajadas en Estocolmo, Kuala Lumpur y Madrid. De este modo, el 15 de septiembre de 1975 un comando palestino irrumpía en las instalaciones de la embajada de Egipto en Madrid con el objetivo de ocupar la sede y capturar rehenes. El móvil de la acción terrorista era protestar contra la posición conciliadora que el Egipto de Anwar al-Sadat estaba adoptando con Israel'2.

Aunque ya se habían detectado actividades terroristas y algunos episodios de violencia de grupos de Oriente Próximo desde finales de los sesenta, España se convertía con el secuestro de la embajada egipcia en escenario de un nuevo ciclo de violencia terrorista internacional que tenía dos propósitos estratégicos: por un lado, conseguir objetivos puntuales como lograr la retirada de los delegados egipcios en las negociaciones egipcio-israelíes de Ginebra, y por otro, trasladar el conflicto y la inseguridad más allá de las fronteras del mundo árabe. El secuestro de la embajada egipcia en Madrid fue perpetrado por un comando de cuatro terroristas del denominado "Grupo de Abdel Kader el Husseini"», presumiblemente del entorno del FPLP que, al igual que Septiembre Negro, respondía a la táctica de crear ad hoc grupos terroristas con el fin de realizar una acción determinada.

A nivel táctico podemos señalar que la operación se inició con el asalto de la embajada egipcia, situada en la confluencia de la calles Velázquez y José Ortega y Gasset de Madrid en torno a las 12:00 horas. Tras tomar rehenes (entre los que destacaban el propio embajador, el cónsul y el agregado de prensa) emitieron un comunicado de seis puntos con sus reclamaciones. Al margen de las demandas que respondían a fines estratégicos del radicalismo palestino de mediados de los setenta, un análisis del mencionado comunicado terrorista revela, en su punto quinto, la advertencia a la policía de no intentar liberar por la fuerza las instalaciones de la embajada bajo la amenaza de que uen caso contrario y ante cualquier sospecha el edificio volará". Aunque no se llegaría a comprobar la posesión de explosivos por parte del comando, es reveladora la apelación al componente suicida de unos terroristas que, ajenos ideológicamente a cualquier tipo de fanatismo religioso, querían de este modo enfatizar lo resolutivo de su misión transmitiendo explícitamente esta amenaza a las fuerzas policiales que rodeaban la misión diplomática ${ }^{4}$.

1 Wardlaw, G., Terrorismo político. Teoría, táctica y contramedidas. Madrid, Servicio de Publicaciones del EME, 1986, p. 107

2 Entre 1974 y 1975 Egipto e Israel llegarían a una serie de acuerdos apoyados por el entonces Secretario de Estado norteamericano, Henry Kissinger. El Cairo volvería a abrir el canal de Suez permitiendo el paso de mercancías israelíes. A la par, Israel se retiraría de enclaves estratégicos y algunos campos petrolíferos del Sinaí.

${ }^{3}$ El origen del nombre adoptado por los terroristas procede del de un líder palestino fallecido durante los enfrentamientos de abril de 1948 por el control de Jerusalén.

4 El embajador egipcio declararía días más tarde de su liberación que el grupo asaltante portaba armas cortas y explosivos. 
Tras un proceso de negociación en el que participarían activamente diplomáticos en España de países árabes (Kuwait, Siria, Argelia e Iraq) se resuelve la salida rumbo a Argel del comando y sus rehenes. En la madrugada del día 16 (aproximadamente a las 3:15, quince horas después del inicio del secuestro) el comando terrorista, acompañado de cinco personas (tres de ellas rehenes ${ }^{5}$ ) salieron de la embajada rumbo al aeropuerto de Barajas en un vehículo facilitado por la EMT de Madrid. A las 3:51 el grupo despegaría rumbo a Argel. El avión aterrizaría en Argel a las 5:30 de la madrugada. Tras liberar a los rehenes (el embajador, el cónsul y el agregado de prensa de la embajada egipcia) que habian viajado junto a los embajadores argelino e iraquí, los secuestradores darían una rueda de prensa en el propio aeropuerto en el que se congratularian por el éxito de la operación y eximirían de responsabilidad o conexión con el grupo al resto de organizaciones de la «resistencia palestina».

La presencia de ciudadanos árabes comprometidos con la causa palestina ha sido común durante décadas en las diferentes capitales europeas. De hecho, un grupo de estudiantes de países árabes en Madrid se encontraban realizando una sentada-protesta en las oficinas de la Liga Árabe contra las mencionadas negociaciones egipcio-israelíes cuando recibieron las noticias del secuestro de la embajada egipcia. Al igual que en el resto de Europa, aquel complicado puzzle regional que es Oriente Próximo escenificó en España parte de su enmarañado sistema de alianzas y antagonismos en el que los grupos terroristas jugaban un papel destacado. De este modo, se dieron durante años episodios de violencia como el asesinato el 3 de marzo de 1980 de un abogado español, Adolfo Cotelo, en la calle Eduardo Dato de Madrid. La muerte de Adolfo Cotelo fue fruto de una equivocación al ser confundido por su asesino con el empresario y expresidente de la comunidad judía en España, Max Mazín, verdadero objetivo de la acción.

El terrorista que perpetró el crimen fue el palestino Said Ali Salman, que había entrado en España con pasaporte de Omán y con un visado español expedido por el consulado de Bagdad. Tras su arresto, fue condenado a una sentencia de veintinueve años de cárcel y el incidente deterioró las relaciones hispano-iraquíes. Esta última consecuencia del asesinato del abogado español es debida a que Ali Salman podría haber sido identificado por fuentes palestinas como un terrorista bajo la órbita de Bagdad. De hecho, llegó a trascender que el propio Yasser Arafat, disgustado por un atentado que deterioraba la buena imagen que la "causa palestina" tenía en España, pudo haber confirmado la conexión del terrorista con el régimen baasista de Iraq en una conversación con un diplomático español.

Dos años más tarde sería asesinado en Madrid el palestino Nabil Arankj Wadi. Se trataba de un activista asentado en España que recibió dos disparos en la nuca a plena luz del día en la calle Guillermo de Osma el 1 de marzo de 1982. Nabil

"Los asaltantes retuvieron a los tres rehenes más "valiosos" dejando libres al resto del personal de la embajada. 
Arankj Wadi habría militado en Al Fatah y mantenía vínculos con personas próximas a grupos como Abu Nidal, el FDLP y el FPLP. Este historial haria que la OLP emitiese un comunicado acusando al Mossad de haber ejecutado la acción. No obstante, la hipótesis más probable apunta a que el crimen pudo haber sido causado por rivalidades en el seno de los grupos palestinos más radicalizados.

En está última línea, también se especuló sobre la posibilidad de que elementos de Abu Nidal en España hubieran prestado apoyo logístico en la perpetración del asesinato con la instigación del régimen de Hafiz al-Assad. De este modo, los servicios secretos sirios habrían influido en la cúpula de Abu Nidal para neutralizar a un Nabil Arankj Wadi que habría incluido en su círculo de relaciones en España a miembros de la oposición islamista siria de los Hermanos Musulmanes en el exilio. Esta última hipótesis se sustentaría sobre la posibilidad de que Arankj Wadi pertenecía al denominado Movimiento Popular de Liberación Árabe (cercano a la órbita iraquí) y que con el apoyo de Bagdad (uno de los principales rivales regionales de Damasco) se habría acercado peligrosamente a los islamistas sirios ${ }^{6}$. Aunque los informes policiales derivados del análisis del arma empleada (encontrada en los lavabos de una cafetería de la plaza de Callao) no concluyeron más que se trataba de una pistola del calibre 9 corto, de marca extranjera y con la numeración borrada, la policía mantuvo siempre el móvil político como causa de su asesinato.

Poco más de un mes después, el 15 de abril de 1982, se produjeron en Madrid una cadena de explosiones. Aunque en un principio los servicios de información sospecharon de grupos armenios activos en España desde hacia algunos años ${ }^{7}$, los objetivos seleccionados (las instalaciones de la compañía aérea jordana en el edificio "Torre de Madrid" y la líneas aéreas egipcias en la calle de Alcalá) y la táctica empleada (que no incluyó la rápida reivindicación del atentado tal y como venían realizando los armenios) hicieron que se desechase la autoria armenia en las líneas de investigación. Se planteó que los incidentes podían estar relacionados con la evacuación del Sinaí por Israel tras el establecimiento de relaciones diplomáticas en 1980 entre este país y Egipto. Las explosiones se produjeron en torno a la 1:30 de la madrugada. Aunque los autores avisaron telefónicamente de la colocación de una de las dos bombas no se produjo reivindicación alguna. Días después, el 27 de abril, el agregado cultural sirio en Madrid, Hassan Dayoub, fue ti-

6 Los Hermanos Musulmanes sirios fueron los principales opositores al régimen de Hafiz al-Assad. Es necesario recordar que este asesinato se ejecuta un mes después de la masacre de Hama. También podríamos señalar, aunque no existe mucha información al respecto, que algunos medios se harían eco de fuentes diplomáticas españolas para responsabilizar a agentes de Damasco como los ejecutores un año antes (21-11-1981) del asesinato en Barcelona del dirigente de los Hermanos Musulmanes sirios, Nizar Sabag.

7 Aunque su atentado más violento en España fue el perpetrado en junio de 1978 contra el embajador turco en Madrid que le costó la vida a la mujer del representante diplomático de Ankara, a otro familiar y al chófer de éstos, los objetivos preferenciales de los terroristas armenios en nuestro país fueron durante años las líneas aéreas occidentales. Podríamos enumerar: noviembre de 1979 (British Airways y TWA), enero de 1980 (TWA, British Airways, Swissair y Sabena), octubre de 1980 (Alitalia), diciembre de 1980 (Swissair y TWA) y noviembre de 1981 (Swissair). 
roteado en un atentado terrorista cuando se disponía a aparcar su vehículo en su residencia de la plaza del Doctor Laguna. Hassan Dayoub logró repeler la agresión con el revolver que portaba ${ }^{8}$.

El 8 de agosto de 1982 instalaciones ligadas a empresas norteamericanas en Madrid y Barcelona fueron objeto de artefactos explosivos. Las investigaciones apuntaron a grupos palestinos que actuaban en Europa en relación con el conflicto del Líbano. La primera explosión se produjo a la 1:07 de la madrugada en los almacenes Sears de la avenida Meridiana de Barcelona. La bomba fue colocada en una de las puertas del edificio y causó desperfectos materiales de mediana importancia en las instalaciones de la empresa y en algunas viviendas próximas. En Madrid, el artefacto explosivo iría dirigido contra las oficinas del Bank of America situado en la calle Capitán Haya. El paquete que contenía el explosivo estaba simulado en una bolsa de plástico y fue colocado en unos setos próximos. Un dato revelador de que podría tratarse de un ataque simultáneo es que el material utilizado para fabricar los explosivos de Madrid y Barcelona era similar (pólvora prensada). Aunque no se reivindicarían por ningún grupo, se interpretó que estos atentados, que buscaban llamar la atención provocando destrozos materiales, iban dirigidos contra intereses norteamericanos por la postura mediadora de Washington en Libano. Durante esas mismas fechas, estudiantes palestinos y libaneses iniciarían una jornada de protesta con encierros en Madrid para exigir la salida de las tropas de Israel del Líbano ${ }^{9}$.

En aquel clima de tensión internacional, el 16 de septiembre de 1982 era asesinado un diplomático a las puertas de la embajada de Kuwait en Madrid por un activista palestino perteneciente a la organización Abu Nidal. Es necesario recordar cómo el propio Abu Nidal había declarado desde su marcha de Al Fatah su disposición de atentar no sólo contra los enemigos de la "causa palestina" sino también contra todos los "traidores" a la misma. Entre los objetivos de sus acciones se encontrarían todas aquellas voces que, desde el propio mundo árabe, apostaron por la negociación o el acercamiento de posturas con Israel. Abu Nidal contaría en España con una estructura de apoyo integrada por activistas asentados en nuestro país y que ya habrían prestado apoyo logístico a terroristas desplazados a nuestro territorio. Este modus operandi, en el que los terroristas llegaban a España ex profeso para la perpetración de atentados, contaría con al menos un precedente: el asesinato de Nabil Arankj Wadi el mes de marzo anterior.

\footnotetext{
${ }^{8}$ Al margen de sus actividades culturales, Dayoub habría ejercido en Madrid la jefatura del partido baasista sirio y responsabilidades en materia de inteligencia. Todo ello podría permitimos deducir que en aquel entonces estuviera asumiendo funciones de control de la oposición siria en el exilio.

${ }^{9}$ En aquellos momentos Washington negociaba el fin del cerco a Beirut por el ejército israeli. Ello permitiría a los líderes de la OLP abandonar la ciudad iniciando de este modo su exilio a Túnez. Las negociaciones incluían el despliegue de una fuerza multinacional encabezada por EEUU que no era bien vista por líderes radicales palestinos como Nayef Hawatmeh (secretario general del FDLP). Aquella mediación internacional no pudo rebajar el nivel de violencia en el conflicto y al mes siguiente las milicias cristianas libanesas atacaron el campamento de refugiados palestinos de Sabra y Shatila.
} 
Según declaró el terrorista detenido por la policía como autor del atentado, sus jefes en Abu Nidal le habian transmitido la orden de asesinar al embajador kuwaitín. Para ello se había trasladado desde Turquía a España cuatro meses atrás y había contado con la ayuda de la red de apoyo de Abu Nidal en España para recabar información y planificar el atentado. Precisamente esta célula de apoyo fue la que le entregó la pistola Beretta con la que asesinó al secretario de embajada kuwaití, Sayed Hassan Najeb, que en aquellos momentos ocupaba la responsabilidad de embajador en funciones al encontrarse el titular de viaje. Aquel atentado, perpetrado a las puertas de la embajada kuwaiti en la plaza de Cuzco de Madrid, respondía a una estrategia diseñada por el radicalismo palestino que pretendería forzar al emirato árabe a abandonar su política moderadora en el conflicto de Próximo Oriente. Precisamente, horas antes del asesinato de Madrid, el vicecónsul de Kuwait en Karachi era objeto de un atentado en el que resultaba levemente herido. Asimismo, el 4 de julio anterior había sido asesinado en Nueva Delhi el secretario de embajada de Kuwait y el 28 de abril había sido desactivado un artefacto explosivo ante la representación diplomática kuwaití en La Haya ${ }^{11}$.

El 21 de septiembre de 1982 un artefacto explosivo de alta potencia provocó cuantiosos daños materiales en el Centro Cultural Iraquí de Madrid. Los especialistas en explosivos de la Policía Nacional determinaron que la bomba había sido fabricada con una carga explosiva de una potencia equivalente a cuatro kilos de Goma 2. La policía terminó atribuyendo el atentado contra el Centro Cultural Iraquí de Madrid a la célula islamista integrada por chíes iraníes, que se neutralizaría en el verano de 1984: el 24 de julio de ese año se logró desarrollar con éxito un operativo antiterrorista que permitió neutralizar a un comando de chiíes radicales antes de que perpetrasen en nuestro pais una cadena de atentados (en el aeropuerto de Barajas habrian pretendido secuestrar un avión de la Saudi Arabian Airlines y en EI Prat de Barcelona estarían preparando el ataque con granadas contra un avión de pasajeros en el momento del despegue).

Esta operación se habría puesto en marcha a mediados de 1982, cuando fue detenido en el aeropuerto de Orly un ciudadano irani vinculado con grupos chíes terroristas. En poder de aquel viajero se encontró el nombre de un iraní asentado en España, Sayab Jabar Hoseini, y la información fue trasladada a la policía española vía Interpol. Las alertas antiterroristas vieron materializada la amenaza cuando dos

${ }^{10}$ La detención la efectuó una patrulla de la policia que acudió al lugar de los hechos con la rapidez suficiente como para que el terrorista viese frustrado su plan de fuga.

11 No obstante, el radicalismo palestino del entomo de Abu Nidal volvería a actuar al año siguiente en Madrid: pocos dias antes de que acabase el año 1983, el 29 de diciembre, era asesinado un funcionario de la sección consular de la embajada de Jordania, Walid Jamal Balkiz, en un atentado reivindicado a France Presse por el grupo denominado Brigadas Revolucionarias Árabes. Este grupo habría perpetrado varios atentados contra representaciones diplomáticas jordanas en diferentes puntos de Europa. Igualmente, habría sido responsable de un atentado contra un avión de pasajeros de la línea KLA Gulf Air el 23 septiembre de 1983 en el que perecerian 111 personas. En una linea estratégica similar a Abu Nidal, el móvil de las denominadas Brigadas Revolucionarias Árabes contra objetivos jordanos era el acercamiento de Ammán a Jerusalén en el tablero de Oriente Próximo. 
activistas chíes radicales fueron sorprendidos el 18 de noviembre de 1982 colocando dos artefactos explosivos en el parque del Retiro de Madrid ${ }^{12}$. Los servicios de información de la policía española habían detectado movimiento de activistas chiles en Madrid y Barcelona durante los meses anteriores a las primeras detenciones.

El 5 de abril de 1984 era detenido en Barcelona un falsificador buscado por Interpol, Sandor Alexander Csengery. Aunque no se llegaría a probar la vinculación de Csengery con la célula chií, este falsificador de documentos podría haber facilitado visados falsos para entrar en EEUU y las investigaciones policiales españolas habrían desvelado que entre sus clientes se encontraban ciudadanos iraníes ${ }^{13}$. El 24 de julio de 1984, tras el seguimiento durante meses de elementos sospechosos de la colonia iraní en España (principalmente localizada en Barcelona entre el colectivo de estudiantes universitarios de aquel país ${ }^{14}$ ), se detiene en Madrid al ciudadano iraní Abu Naser Mohamed Rabani (nacido en Teherán en 1960). Rabani acababa de llegar a España y su presencia en el país hizo sospechar a los responsables de la investigación que se trataba de una persona clave que podía activar la trama chí para la perpetración inminente de atentados.

Igualmente, de manera coordinada, eran arrestados en Barcelona otros dos miembros de la célula islamista. Las detenciones se desarrollaron en la estación de Sants cuando Sayed Jabar Hoseini (nacido en Garmad, Irán, en 1955) y Dezfuli Shorab (nacido en Teherán en 1955) se disponían a tomar un tren con destino a Madrid. El operativo continuaría en Barcelona, concretamente en un domicilio en la calle Muntaner vinculado a los detenidos. Allí se procedía al arresto de otro ciudadano irani, Hasani Hassan (nacido en Gon, Irán, en 1959). El registro de este piso de la calle Muntaner hizo que se identificase el centro logístico que permitía operar a la célula tanto en España como en el resto de Europa. De hecho, en esta vivienda y en un segundo piso localizado en la calle de Bobilés de Hospitalet de Llobregat se incautaría el siguiente arsenal: dos lanzagranadas con munición, dos armas automáticas con munición, dos silenciadores, un kilo de explosivo C-4 y varios metros de mecha lenta.

La trama terrorista vincularía a la célula islamista con el régimen de Teherán cuando la policía acusó a Mohamed Jafar Niknam, agregado de asuntos estudiantiles de la embajada de Irán en Madrid, de ser el encargado de suministrar las armas necesarias para el secuestro del avión en Barajas ${ }^{15}$. Las investigaciones

12 Aunque sobre este hecho existe poca documentación, hay que reseñar que el lugar escogido del parque del Retiro era un punto de encuentro de opositores iranies al régimen chií de Teherán.

${ }^{13}$ Los responsables de seguridad de EE.UU. e Israel estaban especialmente atentos ante el inminente inicio de los Juegos Olímpicos de Los Ángeles, inaugurados el 28 de julio de 1984.

14 Colectivo que participaba activamente en manifestaciones y otros actos de protesta en nuestro país. Precisamente muchas de aquellas matriculas universitarias fueron clave en las investigaciones policiales y fuente de información de inteligencia compartida por España con otros servicios de información.

15 Este vínculo con la embajada iraní provocaría un incidente diplomático que se resolvería con la salida de España del agregado, Mohamed Jaafar Nikman. Oficialmente, una vez producidas las detenciones, las autoridades de Teherán colaborarian en el esclarecimiento del caso. 
desvelaron que, posiblemente, el plan diseñado consistía en beneficiarse de la libertad de movimientos del diplomático iraní para realizar en la sala de tránsito o embarque la entrega de las armas a los secuestradores. Una vez que los secuestradores hubiesen tenido el control del aparato, éste sería llevado a Teherán haciendo escala en Niza o Roma. El secuestro habría estado a cargo de Abu Naser Mohamed Rabani y otros tres individuos más a los que se les esperaba en los días siguientes procedentes de Irán.

Por otro lado, el plan que los extremistas chiíes pretendían también poner en práctica en el aeropuerto de Barcelona consistía en utilizar algunos de los dos lanzagranadas incautados para atacar en el momento del despegue un avión de pasajeros. La acción, que pretendería provocar la muerte de la totalidad del pasaje, hubiese estado envuelta en una explosión espectacular si consideramos que el avión estaría en ese momento lleno de combustible. Esta segunda acción terrorista estaba menos ultimada por la célula islamista iraní que el secuestro planeado en Barajas. No obstante, se especuló sobre la posibilidad de que los tres detenidos en Barcelona hubiesen sido los agentes encargados de perpetrar la matanza. Aquella célula, en la que Mohamed Jafar Niknam habria desempeñado un papel clave, se adscribió al grupo denominado "Fedayín del Islam" integrado por activistas islamistas del entorno chií radical. De hecho, el propio Mohamed Niknam habría mostrado en su círculo cercano sus simpatías por Hezbollah y sus tácticas ${ }^{16}$. Mohamed Jafar Niknam fue expulsado de España el 27 de julio y marchó rumbo a Ginebra en un avión de Swisair.

La célula desarticulada habría tenido entre sus objetivos no sólo la realización de atentados en Europa, sino también se habría encargado del apoyo logístico y obtención de información para otros comandos ${ }^{17}$. Para hacer frente a la amenaza del terrorismo islamista, el entonces CESID en colaboración con el Mossad habría puesto en marcha, en agosto de 1984, una investigación para poder localizar en nuestro territorio células de apoyo a grupos terroristas chíes. Ese mismo mes (508-1984) se producía el asesinato frustrado del millonario kuwaití Al Marzook en la Costa del Sol. El 17 de agosto Zaki al Halou, dirigente del FPLP, es herido en Madrid de un disparo en la cabeza cuando circulaba en un coche por la confluencia del paseo de la Castellana con la calle Carlos Maurrás. Ambos atentados fueron reivindicados por un grupo autodenominado Vanguardia Islámica Revolucionaria.

16 Un año antes, el 23 de octubre de 1983, centenares de soldados franceses y norteamericanos fueron asesinados durante una ofensiva terrorista del grupo radical chii Hezbollah en Beirut. La táctica empleada fue la del ataque suicida coordinado, contra dos blancos prefijados, empleando camiones con explosivos. Muchos especialistas consideran que aquel dia comenzó una nueva época del terrorismo en la que se aplicarian tácticas de las que Al Qaeda ha sido la principal heredera.

17 Entre las acciones que se les atribuyeron en nuestro pais podríamos destacar: el atentado contra el Centro Culfural Iraquí (21-09-82), la acción frustrada con artefacto explosivo en el parque del Retiro (18-11-82), el lanzamiento de una granada anticarro contra la embajada de EEUU (04-02-83) y un ataque contra un avión kuwaití en Barajas (13-09-83). 
Como hemos visto, desde 1982 se habrían ido asentando en España activistas chiíes (principalmente en la Costa del Sol, Granada, Madrid, Barcelona y Valencia). Los responsables de inteligencia temian que la situación geográfica peninsular pudiese estar convirtiendo a España en una base operativa para estos grupos islamistas. Los esfuerzos se centraban en intentar localizar células de apoyo chiíes que pudiesen estar relacionados con la Jihad Islámica (una de las «firmas" del grupo chii proiraní Hezbollah). La estructura que se podría haber establecido en nuestro país integraría a chiíes iraníes y libaneses. Éstos prestarian su cobertura a terroristas aislados que vendrian a España a cometer atentados o planificar operaciones en nuestro país o en otros puntos de Europa. El 14 de septiembre de 1984 un ingeniero saudi fue asesinado en un atentado perpetrado en una cafetería de Marbella. Aquel atentado, en el que también resultaron heridos otros dos compatriotas de la víctima, fue atribuido a la mencionada Jihad islámica ${ }^{18}$. Esta organización también podría haber estado detrás del atentado en Madrid, el 3 de noviembre de 1984, contra el ciudadano libanés Elías Joussef Assald.

Por otro lado, esta oscura amalgama de comandos procedentes de terrorismo islamista de orientación chií radical que operaban en Europa había perpetrado, el 24 de julio de 1984, un atentado en Barcelona contra el consulado francés. Este ataque, llevado a cabo con explosivos, no había provocado ninguna víctima mortal en la representación diplomática francesa en la ciudad condal ${ }^{19}$. Sería en septiembre de 1984 cuando se produjera una cadena de sucesos, presumiblemente relacionados, entre Madrid y Beirut: el intento de asesinato de un funcionario de la embajada Libia en Madrid, la detención de los autores y el secuestro del embajador español en Beirut (todo ello contextualizado en uno de los momentos de mayor violencia en el conflicto del Líbano).

El primer eslabón de esta cadena de sucesos ocurriría el 12 de septiembre de 1984, cuando un funcionario de la representación diplomática Libia en Madrid fue víctima de un atentado presuntamente perpetrado por dos terroristas de nacionalidad libanesa. Los dos libaneses detenidos, Mustafá Alí Calí y Mohamed Khair Abbag Ramal, habrían actuado contra el diplomático debido a su posible vinculación con los servicios de inteligencia de Trípoli y justificarían la acción como una respuesta a la presunta implicación de Libia en la desaparición del líder chí́, Musa Sadr. En Beirut un grupo islamista chií, las Brigadas del imán Musa Sadr, reivindicaron el atentado ${ }^{20}$.

Como hemos señalado anteriormente, Líbano era escenario de multitud de secuestros de ciudadanos extranjeros. Por ello, tanto la inteligencia israelí como la norteamericana advirtieron a Madrid sobre la posibilidad de que algún ciudadano español pudiese ser objeto de un secuestro con el que poder canjear la liberación

18 Base de datos del Institute for the Prevention of Terrorism (MIPT). Disponible en <http://db.mipt.org> [Consulta: agosto 2004].

19 Ibidem. [Consulta: septiembre 2004].

20 Las Brigadas del imán Musa Sadr estarían vinculadas con grupos del radicalismo chí libanés e iraní. 
de los dos detenidos por las fuerzas de seguridad españolas. De hecho, ese mismo mes de septiembre la Jihad islámica emitió un comunicado en el que instaba a España a «liberar inmediatamente a nuestros dos camaradas pertenecientes a las Brigadas del imán Musa Sadr". Las autoridades líbanesas comprobarían que el peligro de un atentado terrorista de firma chií amenazaba la seguridad de los diplomáticos españoles en Libano. Por ello, trasladaron al edificio de la embajada española una dotación de soldados con tanquetas para garantizar la seguridad de los españoles. Según informó la agencia EFE, miembros de las Brigadas del imán Musa Sadr solicitaron al embajador español, Pedro de Aristegui, la liberación de los islamistas detenidos en España a cambio de comprometerse a no volver a actuar en territorio español. El propio embajador les habría advertido que el proceso iniciado en España, donde los detenidos estaban ingresados en Carabanchel a la espera de ser juzgados en la Audiencia Nacional, no podía ser interrumpido y cualquier negociación en este sentido no era viable.

La situación era cada vez más tensa y ante la posibilidad de que se produjeran enfrentamientos armados entre activistas islamistas y fuerzas del orden libanesas en las inmediaciones de la embajada española, el Ministerio de Asuntos Exteriores, a instancias del embajador, trasladó al personal diplomático y administrativo hacia el sector cristiano de Beirut. El 10 de octubre el vehículo del embajador fue interceptado por unos terroristas: el secuestro duraria sólo unas pocas horas y la prensa de la época no aportó muchos detalles sobre el contenido de las negociaciones que podría haber mantenido el Ejecutivo español para liberar al diplomático. No obstante, sabemos que la liberación se produjo cuatro horas más tarde de ser secuestrado ${ }^{21}$.

La representación diplomática española en Líbano no dejaría de ser un objetivo terrorista chii durante algunos años: en 1986, las mencionadas brigadas del imán Musa Sadr perpetraron un ataque contra una caravana de vehículos que habían recogido en el aeropuerto de Beirut a un contingente de los GEO destinados a proteger nuestra embajada. Los terroristas interceptaron el convoy y secuestraron al canciller Assad Abdo, el vicecanciller Gaspar Abdo y a uno de los miembros del GEO, Pedro Antonio Sánchez. Tras varias semanas, las negociaciones del embajador permitirian liberar a los tres secuestrados ${ }^{22}$. A punto de concluir la guerra, el 15 abril de 1989, un proyectil caía en el patio de la embajada de España. Pedro de Arístegui falleció en el ataque. Junto a él, dos de sus familiares y un miembro de la seguridad de la embajada murieron en la agresión. La esposa del embajador de España resultó gravemente herida ${ }^{23}$.

21 Gustavo de Arístegui señala a este respecto que «el secuestro, vistos los antecedentes de otros similares, podía llegar a durar años. Por suerte, los contactos y la información del embajador funcionaron y él, que casi sabía de antemano a qué dos o tres lugares podían llevarlo en caso de secuestro, le pasó la información a Nabí Berri, quien mandó a un comando de la milicia Amal que encontró al embajador en el primero de los lugares que él habia apuntado como posible piso franco y lo liberó", en ARístEGUI, G. El islamismo contra el islam, Barcelona: Ediciones B, 2004, p. 312.

22 Ibidem.

23 Oficina de Información Diplomática. República del Libano. En Monogratías de la OID, julio de 2004. Disponible en <http://www.mae.es> [Consulta: agosto 2004]. 
Volviendo a España y retrocediendo a 1985, las fuerzas y cuerpos de seguridad españoles habían emprendido, tal y como hemos descrito, operaciones antiterroristas con el fin de neutralizar la oscura red de apoyo que radicales chiíes, de procedencia principalmente libanesa e iraní, habían ido tejiendo en nuestro territorio. Con el conflicto del Líbano como telón de fondo, en el que el secuestro de extranjeros y los atentados indiscriminados perpetrados por suicidas se habian ido incorporado al know-how del terrorismo ${ }^{24}$, los comandos islamistas incrementaron a partir de 1983 el nivel de violencia en sus acciones y "cruzaron", en abril de 1985, la línea que el terrorismo perpetrado por radicales procedentes del mundo árabo-islámico en España había respetado desde años antes: evitar daños colaterales humanos o buscar victimas entre ciudadanos españoles.

Así, el 12 de abril de 1985, se produciria el atentado contra el restaurante La Casa de las Costillas-El Descanso, cercano a la base de Torrejón y que era frecuentado por personal militar norteamericano. El atentado provocó dieciocho muertos y cerca de cien heridos -entre las víctimas mortales no hubo ningún ciudadano estadounidense $-y$ fue reivindicado por el grupo Jihad islámica ${ }^{25}$. Esta reivindicación, que fue a la que se prestó mayor credibilidad de las múltiples que se produjeron, se efectuó a la agencia Associated Press de Beirut al día siguiente del atentado. La voz que reivindicó para Jihad islámica el ataque justificó la acción como respuesta por el coche-bomba explosionado en Bir al Abed el 8 de marzo de 1985; aquella explosión acabó con la vida de varios líderes islamistas y se produjo en una zona libanesa de control israelí bajo las sospechas de que la inteligencia norteamericana podría haber adiestrado a los autores del atentado.

La explosión del restaurante El Descanso se produjo a las 22:45 horas del día 12 de abril. A esa hora la mayor parte de los clientes del local eran de nacionalidad española. Según los trabajadores del restaurante, la clientela se dividía entre norteamericanos y españoles según las costumbres horarias del país. De este modo, entre las 19:00 y las 21:00 horas EI Descanso estaba habitualmente repleto de estadounidenses de la cercana base aérea de Torrejón. Este dato sería observado por los investigadores a la hora de explicarse la inexistencia de víctimas mortales

24 Libano en general y Beirut en particular es a partir de mediados de los ochenta un polvorín el que las facciones enfrentadas implementan la estrategia terrorista con enorme violencia. En este panorama, los islamistas radicales incorporan los objetivos extranjeros y difunden, mediante el terrorismo, el conflicto libanés (con su conexión al árabe-israelí) más allá de los límites de Oriente Próximo. La entrada de tropas de paises occidentales en Líbano, entre las que destacarían las enviadas por Washington, supondría una nueva "afrenta" para las facciones más radicales enfrentadas en el conflicto y entre las que destacarían los chiíes integrados en grupos como la Jihad islámica.

${ }^{25} \mathrm{La}$ ausencia de detenciones hizo que las interpretaciones, investigaciones y los análisis abiertos en aquel entonces fuesen en líneas muchas veces opuestas. Así, a la autoría inicial de ETA, GRAPO o una operación conjunta con el entonces denominado "euroterrorismo", se le sumarian hipótesis más cercanas a las "teorías conspirativas" como la que establecía la vinculación de elementos de la inteligencia israelí en la preparación del atentado. Esta última hipótesis podría haber respondido a la persistente campaña de los responsables de comunicación del activismo palestino que durante los setenta y ochenta adjudicaban por sistema la mayor parte de los atentados contra objetivos árabes u occidentales a un "complot urdido" desde Tel Aviv. 
norteamericanas en un atentado en el que a todas luces aparecían como objetivo. La explicación a este hecho residiría en un fallo en el artefacto explosivo empleado por los terroristas. Expertos en explosivos calificaron el mecanismo empleado de "rudimentario": inicialmente, una de las hipótesis que se manejó es que se pudo haber tratado de un artefacto casero de mecha retardada en vez de relojería. Por otro lado, lo poco sofisticado del artefacto pudo deberse a que los terroristas que perpetraron el ataque eran activistas con menos especialización o con menos materiales.

Lo más probable es que sí se emplease un sistema de relojería de fabricación artesanal compuesto por un reloj despertador y un cable. Igualmente se especuló bastante sobre el hallazgo de polvo en cinco de los cadáveres más cercanos al lugar de la explosión (los lavabos del restaurante). Los análisis químicos de estos restos dedujeron que se empleó cloratita. Ello pudo haber desconcertado a los investigadores que esperaban explosivos y componentes más sofisticados y potentes en un atentado de la Jihad Islámica. La magnitud del atentado pudo deberse a que la localización del explosivo se hallaba detrás de un radiador, en los lavabos de la planta baja, junto a una pared maestra donde se apoyaban las vigas principales del edificio, y la explosión ocasionó el derrumbe de la estructura atrapando a las víctimas. Días después, el presunto hallazgo de pentrita entre los escombros del restaurante haría que se reabriese durante algún tiempo la posibilidad de otras autorías o posibles colaboraciones.

Sea como fuere, es innegable que los terroristas contemplaban la posibilidad de ocasionar víctimas españolas, al menos de naturaleza colateral al objetivo principal. Para explicar este paso hacia adelante del terrorismo islamista de los ochenta en nuestro país, quizás habría que contemplar que los terroristas pretendian no sólo asestar un golpe a EEUU en vísperas de la visita a Madrid del presidente norteamericano Ronald Reagan, sino también dar un «toque de atención» al que hasta entonces habían considerado un "pueblo amigo". En España las movilizaciones en protesta por la visita de Ronald Reagan pueden interpretarse como un preludio del fuerte debate generado en torno a la celebración del referéndum sobre la OTAN de 1986 y es muy posible que el entramado de Jihad Islámica no viese con buenos ojos la permanencia en la Alianza Atlántica de «la tierra de AlAndalus". Como objetivo secundario del atentado, quizás podrían haber perseguido advertir a los españoles sobre las «implicaciones" y "consecuencias» de la permanencia en organismos internacionales como la OTAN, de la posible utilización por parte de EEUU de las bases en territorio español para emprender operaciones antiterroristas o del entonces previsible establecimiento de relaciones diplomáticas con Israel26.

${ }^{26}$ Un año después, en torno al ataque emprendido por EEUU contra objetivos seleccionados en Libia (14-04-1986), se generaria una fuerte polémica en España sobre la posible utilización de las bases hispano-norteamericanas y la penetración en nuestro espacio aéreo de aeronaves estadounidenses que pudieron haber intervenido en los bombardeos. Hemos de recordar que aquel ataque aéreo fue emprendido en virtud de una directiva presidencial estadounidense de abril de 1984 que aprobaba 
Meses más tarde, el 1 de julio de 1985, Jihad Islámica volvía a atentar en Madrid. Esta vez el objetivo eran las sedes de líneas aéreas extranjeras en la Gran Vía y la plaza de España. A las 12:16 horas se produjo una explosión en la Gran Vía, a la altura de las instalaciones de la British Ainways. Minutos más tarde, un comando disparó con armas automáticas contra la sede de las Líneas Aéreas Jordanas (ALIA) ubicadas en el edificio "Torre de Madrid» de la plaza de España. Tras abrir fuego lanzaron una granada de mano en el interior de las instalaciones y aunque el dispositivo de la granada de mano falló, resultaron heridas dos personas a consecuencia del ametrallamiento (una empleada de la agencia y un cliente). Aquellos ataques terroristas coordinados de Madrid evidenciaron nuevamente la estrategia del terrorismo islamista de actuar en España sin evitar daños humanos entre la población, pues se contó una víctima mortal y alrededor de veintiséis heridos de diversa consideración.

El 27 de junio de 1986 un vuelo Madrid-Tel Aviv de la compañia aérea israeli $E I A /$ era objeto de un atentado frustrado. El jefe del servicio de seguridad de $E I A I$ evitó que el artefacto explotase en pleno vuelo interceptando al terrorista antes de embarcar en Barajas. Los agentes de seguridad de la compañía advirtieron a los civiles que se encontraban en la terminal que abandonasen el área, evitando así víctimas mortales. Instantes más tarde la bomba, oculta en el equipaje de mano del terrorista, estalló en el mostrador de la línea aérea israelí provocando trece heridos. Las investigaciones condujeron al entorno del radicalismo palestino, concretamente al grupo de Abu Mussar, líder de la facción palestina que perpetró el ataque, que entonces se encontraba en Siria. Los medios de comunicación españoles analizaron el incremento de la violencia del terrorismo internacional en nuestro país. De manera que, refiriéndose al atentado del restaurante El Descanso, un editorial del diario El País del 14 de abril de 1985 señalaba que "cabría establecer una relación causal entre un eventual atentado contra ese restaurante y la decisión del Gobierno de aconsejar la permanencia en la OTAN ${ }^{27}$. Por otro lado, Diario 16 editorializaría esta ola de violencia señalando, el 3 de julio de 1985, que "la sensibilidad española a la hora de reconocer al Estado de Israel no se ha visto correspondida por quienes controlan, arman, protegen o toleran a los terroristas. Y, en cualquier caso, nuestros dispositivos de seguridad han de acentuar sus cautelas ante la evidencia de que España se está convirtiendo en un centro logístico de un terrorismo internacional sin escrúpulos, que no para en muertes a la hora de buscar eco para sus causas fanáticas» ${ }^{28}$.

No obstante, a día de hoy, carecemos de indicios firmes que nos permitan explicar el giro estratégico de un tipo de terrorismo que hasta entonces había evitado

y regulaba las acciones contra los Estados "promotores, inductores o cómplices en acciones terroristas que afectan a ciudadanos y bienes norteamericanos en cualquier parte del mundo", en OBRADOR SERRA, F.: La acción norteamericana contra Libia, Boletín de Información del CESEDEN, Madrid, Ministerio de Defensa, octubre de 1986, n. ${ }^{\circ} 195$.

27 El País, «Una matanza escalofriante», 14 de abril de 1985, p. 14.

${ }^{28}$ Diario 16, «España y el terrorismo internacional», 3 de julio de 1985, p. 2. 
provocar víctimas españolas. De hecho, el atentado del restaurante El Descanso logró conmocionar a la opinión pública por las dimensiones de la tragedia, pero las interpretaciones más profundas no salieron de los ámbitos especializados. Esto se explicaría, en gran parte, a que no se percibió aquella nueva tipología de terrorismo como un peligro de mayor inminencia que el de carácter doméstico de ETA o GRAPO, por entonces en una etapa de gran virulencia. El fenómeno remitiria probablemente, influido por el propio devenir de la política internacional y, aunque se dieron algunos nuevos episodios de terrorismo ${ }^{29}$, la amenaza islamista no volvería a ser visible en España hasta comienzos de la década de los noventa. Los jihadistas argelinos empezarían a utilizar el territorio español como base de apoyo y lugar de tránsito en sus acciones en Francia. Aquellos serían los primeros brotes, en nuestro territorio, de lo que hoy denominamos como la Jihad Global.

Principales acciones perpetradas en España por grupos terroristas procedentes del mundo arabo-islámico durante las décadas de los setenta y ochenta ${ }^{30}$

\begin{tabular}{c|c|l}
\hline 1971 & 24.08 .71 & $\begin{array}{l}\text { Grupo: «Al Fatah» } \\
\text { Víctimas mortales: 0 } \\
\text { Heridos: 0 } \\
\text { Objetivo: Lineas aéreas } \\
\text { Táctica: Explosivos } \\
\text { Descripción: Atentado contra un B707 de las líneas aéreas jorda- } \\
\text { nas en el aeropuerto de Barajas. }\end{array}$ \\
\hline 1975 & 15.09 .75 & $\begin{array}{l}\text { Grupo: «Abdel Kader el Husseini» } \\
\text { Víctimas mortales: 0 } \\
\text { Heridos: 0 } \\
\text { Objetivo: Diplomático } \\
\text { Táctica: Secuestro } \\
\text { Descripción: Asalto y ocupación de la embajada de Egipto en Ma- } \\
\text { drid. Los rehenes fueron liberados tras la salida del país del co- } \\
\text { mando terrorista. }\end{array}$ \\
\hline 1980 & $\mathbf{0 3 . 0 3 . 8 0}$ & $\begin{array}{l}\text { Grupo: Desconocido } \\
\text { Víctimas mortales: 1 } \\
\text { Heridos: 0 } \\
\text { Objetivo: Comunidad hispano-judia } \\
\text { Táctica: Ataque con arma de fuego } \\
\text { Descripción: El terrorista fue detenido; pretendia atentar contra la } \\
\text { vida del expresidente de la comunidad judia en España, Max Mazín. } \\
\text { Por error, fue asesinado el abogado Adolfo Cotelo. }\end{array}$ \\
\hline
\end{tabular}

29 Uno de los últimos episodios de este ciclo sería la detención el 23 de noviembre de 1989 en Valencia y Madrid de tres ciudadanos libaneses, cuatro iraquíes y un sudanés pertenecientes a una red terrorista de orientación chií radical. Al grupo se le intervino explosivo C-4, granadas de mano y detonadores. Estarían relacionados con miembros de Hezbollah y con dirigentes de la comunidad chif en Europa.

${ }^{30}$ No se han incluido los atentados perpetrados por grupos de origen armenio. 
Principales acciones perpetradas en España por grupos terroristas procedentes del mundo arabo-islámico durante las décadas de los setenta y ochenta

(Continuación)

\begin{tabular}{|c|c|c|}
\hline 1981 & 21.11 .81 & $\begin{array}{l}\text { Grupo: Desconocido } \\
\text { Víctimas mortales: } 1 \\
\text { Heridos: } 0 \\
\text { Objetivo: Islamistas sirios. } \\
\text { Táctica: Ataque con arma de fuego } \\
\text { Descripción: Asesinato del dirigente de los Hermanos Musulmanes } \\
\quad \text { sirios, Nizar Sabag. }\end{array}$ \\
\hline \multirow[t]{4}{*}{1982} & 01.03 .82 & $\begin{array}{l}\text { Grupo: Desconocido } \\
\text { Víctimas mortales: } 1 \\
\text { Heridos: } 0 \\
\text { Objetivo: Activistas palestinos } \\
\text { Táctica: Ataque con arma de fuego } \\
\text { Descripción: Asesinato de Nabil Arankj Wadi, fruto de posibles ri- } \\
\quad \text { validades en el seno de los grupos palestinos más radicalizados. }\end{array}$ \\
\hline & 15.04 .82 & $\begin{array}{l}\text { Grupo: Desconocido } \\
\text { Víctimas mortales: } 0 \\
\text { Heridos: } 0 \\
\text { Objetivo: Líneas aéreas } \\
\text { Táctica: Explosivo } \\
\text { Descripción: Atentados en Madrid contra instalaciones de la com- } \\
\quad \text { pañía aérea jordana en el edificio "Torre de Madrid" y las líneas } \\
\quad \text { aéreas egipcias en la calle de Alcalá. }\end{array}$ \\
\hline & 27.04 .82 & $\begin{array}{l}\text { Grupo: Desconocido } \\
\text { Víctimas mortales: } 0 \\
\text { Heridos: } 1 \\
\text { Objetivo: Diplomático } \\
\text { Táctica: Ataque con arma de fuego } \\
\text { Descripción: El agregado cultural sirio en Madrid, Hassan Dayoub, } \\
\quad \text { fue tiroteado en un atentado terrorista cuando se disponia a } \\
\text { aparcar su vehículo en su residencia de la plaza del Doctor La- } \\
\text { guna. }\end{array}$ \\
\hline & 08.08.82 & $\begin{array}{l}\text { Grupo: Desconocido } \\
\text { Víctimas mortales: } 0 \\
\text { Heridos: } 0 \\
\text { Objetivo: Empresas norteamericanas } \\
\text { Táctica: Explosivo } \\
\text { Descripción: Instalaciones ligadas a empresas norteamericanas } \\
\quad \text { en Madrid y Barcelona fueron objeto de artefactos explosivos. } \\
\text { Las investigaciones apuntaron a grupos palestinos que actuaban } \\
\text { en Europa en relación con el conflicto del Líbano. }\end{array}$ \\
\hline
\end{tabular}


Principales acciones perpetradas en España por grupos terroristas procedentes del mundo arabo-islámico durante las décadas de los setenta y ochenta

(Continuación)

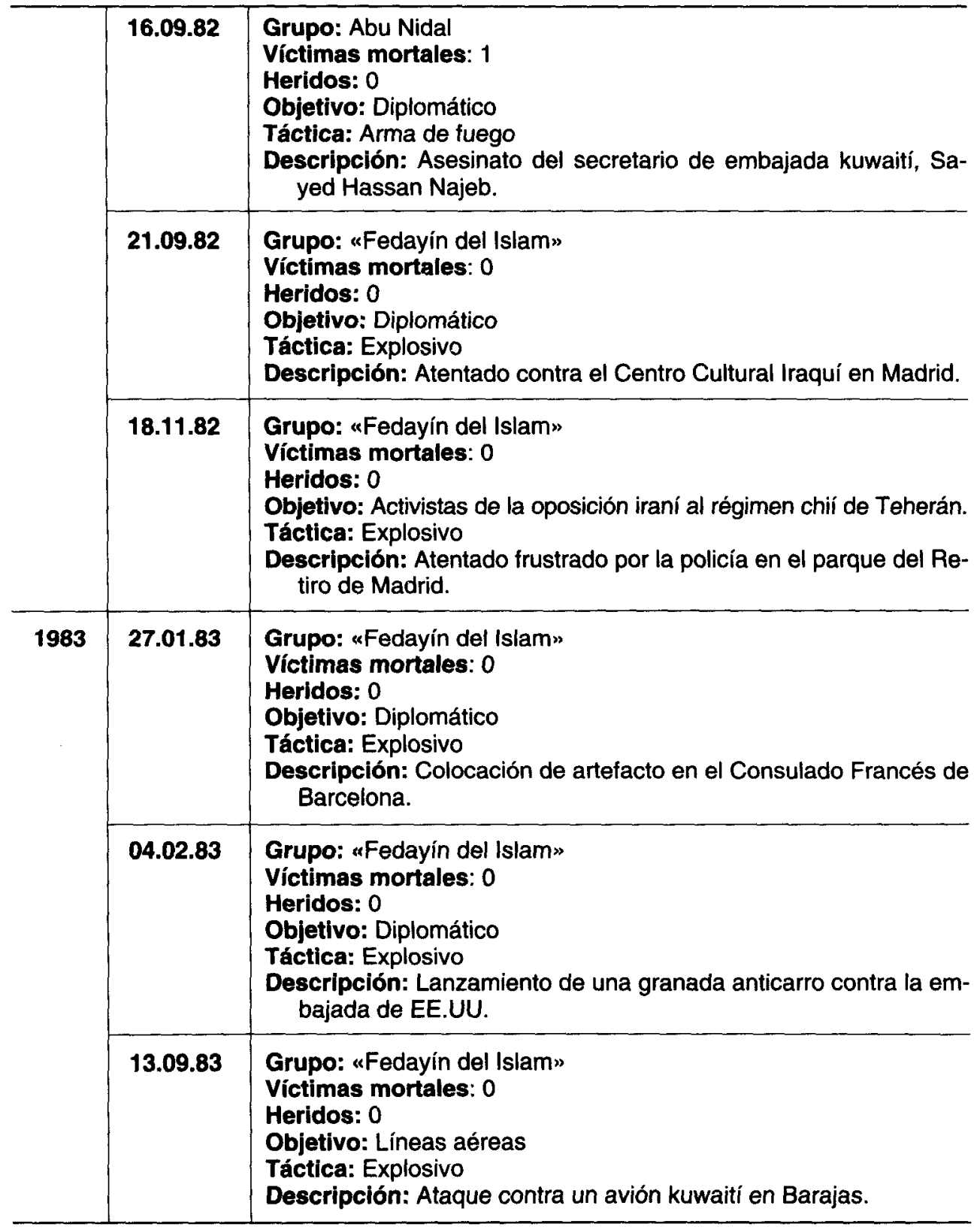


Principales acciones perpetradas en España por grupos terroristas procedentes del mundo arabo-islámico durante las décadas de los setenta y ochenta (Continuación)

\begin{tabular}{|c|c|c|}
\hline & 29.12 .83 & $\begin{array}{l}\text { Grupo: «Brigadas Revolucionarias Árabes» } \\
\text { Víctimas mortales: } 1 \\
\text { Heridos: } 0 \\
\text { Objetivo: Diplomático } \\
\text { Táctica: Arma de fuego } \\
\text { Descripción: Asesinato de Walid Jamal Balkiz, funcionario de la } \\
\text { sección consular de la embajada de Jordania en Madrid. }\end{array}$ \\
\hline \multirow[t]{5}{*}{1984} & 24.07 .84 & $\begin{array}{l}\text { Grupo: Desconocido } \\
\text { Víctimas mortales: } 0 \\
\text { Heridos: } 0 \\
\text { Objetivo: Diplomático } \\
\text { Táctica: Explosivo } \\
\text { Descripción: Atentado contra el consulado francés en Barcelona. }\end{array}$ \\
\hline & 05.08 .84 & $\begin{array}{l}\text { Grupo: «Vanguardia Islámica Revolucionaria» } \\
\text { Víctimas mortales: } 0 \\
\text { Heridos: } 1 \\
\text { Objetivo: Ciudadano kuwaití } \\
\text { Táctica: Arma de fuego } \\
\text { Descripción: Atentado frustrado del millonario kuwaití, Al Marzook, } \\
\quad \text { en la Costa del Sol. }\end{array}$ \\
\hline & 17.08 .84 & $\begin{array}{l}\text { Grupo: «Vanguardia Islámica Revolucionaria» } \\
\text { Víctimas mortales: } 0 \\
\text { Heridos: } 1 \\
\text { Objetivo: Activistas palestinos } \\
\text { Táctica: Arma de fuego } \\
\text { Descripción: Atentado en Madrid contra el dirigente del FPLP, Zaki } \\
\quad \text { al Halou. }\end{array}$ \\
\hline & 12.09.84 & $\begin{array}{l}\text { Grupo: Brigadas del imán Musa Sadr } \\
\text { Víctimas mortales: } 0 \\
\text { Heridos: } 1 \\
\text { Objetivo: Diplomático } \\
\text { Táctica: Arma de fuego } \\
\text { Descripción: Atentado contra un funcionario de la embajada Libia } \\
\quad \text { en Madrid. }\end{array}$ \\
\hline & 14.09 .84 & $\begin{array}{l}\text { Grupo: «Jihad islámica» } \\
\text { Víctimas mortales: } 0 \\
\text { Heridos: } 1 \\
\text { Objetivo: Activistas palestinos } \\
\text { Táctica: Arma de fuego } \\
\text { Descripción: Atentado en Madrid contra el dirigente del FPLP, Zaki } \\
\quad \text { al Halou. }\end{array}$ \\
\hline
\end{tabular}


Principales acciones perpetradas en España por grupos terroristas procedentes del mundo arabo-islámico durante las décadas de los setenta y ochenta

(Continuación)

\begin{tabular}{l|l|l}
\hline 03.11 .84 & $\begin{array}{l}\text { Grupo: «Jihad islámica» } \\
\text { Víctimas mortales: 0 } \\
\text { Heridos: 1 } \\
\text { Objetivo: Ciudadano libanés } \\
\text { Táctica: Arma de fuego } \\
\text { Descripción: Atentado en Madrid contra el ciudadano libanés, Elias } \\
\text { Joussef Assald. }\end{array}$ \\
\hline 1985 & 12.04 .85 & $\begin{array}{l}\text { Grupo: «Jihad islámica» } \\
\text { Víctimas mortales: 18 } \\
\text { Heridos: 84 } \\
\text { Objetivo: Miembros del ejército norteamericano } \\
\text { Táctica: Explosivo } \\
\text { Descripción: Atentado del restaurante El Descanso. No hubo nin- } \\
\text { gún estadounidense entre las víctimas mortales. }\end{array}$ \\
\hline $\mathbf{0 1 . 0 7 . 8 5}$ & $\begin{array}{l}\text { Grupo: «Jihad islámica» } \\
\text { Víctimas mortales: 1 } \\
\text { Heridos: } 26 \\
\text { Objetivo: Líneas aéreas } \\
\text { Táctica: Explosivo y arma de fuego } \\
\text { Descripción: Ataques contra las instalaciones de la British Airways } \\
\text { y las Líneas Aéreas Jordanas en Madrid. }\end{array}$ \\
\hline 27.06 .86 & $\begin{array}{l}\text { Grupo: «Abu Mussar» } \\
\text { Víctimas mortales: 0 } \\
\text { Heridos: 13 } \\
\text { Objetivo: Lineas aéreas } \\
\text { Táctica: Explosivo } \\
\text { Descripción: Ataques contra las instalaciones de El Al en el aero- } \\
\text { puerto de Barajas. }\end{array}$ \\
\hline
\end{tabular}

\section{BIBLIOGRAFÍA}

ArístegUI, G.: El islamismo contra el islam, Barcelona, Ediciones B, 2004.

AVILÉS FARAÉ, J.: " $¿$ Es posible y necesario definir el terrorismo?", conferencia pronunciada en el Seminario Terrorismo: Nuevas manifestaciones. Nuevas respuestas, Universidad de Granada, 18 de abril de 2002. Disponible en <http://www.gees.org> [consulta: octubre 2003].

Avilés FarRÉ, J.: La amenaza del terrorismo islamista en España, Publicaciones de Instituto Universitario de Investigación sobre Seguridad Interior, 4 de marzo de 2003. Disponible en: <http://www. uned.es/investigacion/institutos/instituto_seguridad/IUISI_PUBLICACIONES> [Consulta: marzo de 2004].

Centro Superior de Estudios de la Defensa Nacional,. El Islam: presente y futuro, Madrid: Ministerio de Defensa, Secretaría General Técnica, 1999.

ERLICH, R.: Terrorism As a Preferred Instrument of Syrian Policy, en International Policy Institute for Counter-Terrorism (ICT), 10 de diciembre de 1998 (actualización 10 de octubre de 2001).Disponibles en <http://www.ict.org.il/> [Consulta: julio de 2004]. 
Hoffman, B.: A mano armada: historia del terrorismo, Madrid, Espasa Calpe, 1999.

KELLY, J. H.: Lebanon: 1982-1984, en RAND CORPORATION, U.S. and Russian Policymaking with Respect to the Use of Force, Santa Mónica, RAND Corporation, 1996. Disponible en: <http://www.rand.org> [Consulta: septiembre de 2004].

KEPEL, G.: Fitna. Guerra en el corazón del islam, Barcelona, Paidós, 2004.

-: La yihad. Expansión y declive del islamismo. Barcelona, Península, 2002.

LAQUEUA, W.: Una historia del terrorismo, Barcelona, Paidós, 2003.

López GaRcía, B.: El Mundo Arabo-islámico Contemporáneo, Madrid, Síntesis, 2000.

OBRADOR SERRA, F.: La acción norteamericana contra Libia, Boletín de Información del CESEDEN, Madrid, Ministerio de Defensa, octubre de 1986, n. 195.

WARDLAw, G.: Terrorismo político. Teoría, táctica y contramedidas, Madrid, Servicio de Publicaciones del EME, 1986.

Artículos de prensa de los diarios ABC, Diario 16 y El País entre 1971 y1986. 